\title{
Analizador en línea para un proceso de Extracción por Solvente
}

\author{
Online analyzer for a solvent extraction process \\ Claudio Ayala ${ }^{1} \quad$ José Gallardo $^{2 *} \quad$ Rubén Vásquez $^{3}$ \\ Recibido 15 de julio de 2020, aceptado 1 de septiembre de 2020 \\ Received: July 15, 2020 Accepted: September 1, 2020
}

\begin{abstract}
RESUMEN
Este artículo describe el diseño y construcción de un analizador que permite medir en línea, la razón Orgánico-Acuoso (O/A) y el Tiempo de Separación de Fases (TSF) en un proceso de extracción por solvente. Su principio de funcionamiento se basa en un sistema automatizado que permite adquirir las muestras desde el proceso, para posteriormente ser sometidas a un tratamiento digital de las imágenes capturadas, procedimiento mediante el cual se obtienen ambas mediciones. Los resultados logrados, son promisorios, debido a que el analizador presenta una buena precisión para este tipo de instrumento no convencional, menores a un $2 \%$ de error relativo promedio. Se enfatiza la importancia de medir estas variables operacionales en forma oportuna y precisa, para evitar pérdidas de eficiencia operacional y mantener la recuperación establecida por diseño. Con este nuevo analizador, se pretende que empresas mineras que desarrollan la hidrometalurgia, cuenten con un instrumento de medición en línea que les permita, mejorar la operación de la planta, su eficiencia y recuperación.
\end{abstract}

Palabras clave: Analizador, razón O/A, tiempo de separación de fases, extracción por solventes, imágenes digitales, procesamiento de imágenes.

\begin{abstract}
This article describes the design and construction of an analyzer that allows measurement in line, the Organic-Aqueous ratio (O/A) and the phase separation time (TSF) in a solvent extraction process. Its principle of operation is based on an automated system that allows samples to be acquired from the process, to be later subjected to a digital treatment of the captured images, procedure by which both measurements are obtained. The results achieved are promising, because the analyzer presents a very good precision for this type of non-conventional instrument. The importance of measuring these operational variables in a timely and accurate manner is emphasized, to avoid operational efficiency losses and maintain the recovery established by design. With this new analyzer, it is intended that mining companies that develop hydrometallurgy, have an online measuring instrument that allows them to improve the operation of the plant, its efficiency and recovery.
\end{abstract}

Keywords: Aqueous ratio, phases separation time, solvent extraction, digital images, image processing.

\footnotetext{
1 Universidad de Antofagasta. Departamento de Ingeniería Eléctrica. Antofagasta, Chile. E-mail: claudio.ayala@uantof.cl

2 Universidad Católica del Norte. Departamento de Ingeniería de Sistemas y Computación. Antofagasta, Chile.

E-mail: jgallardo@ucn.cl

3 Politécnico Colombiano Jaime Isaza Cadavid, Facultad de Ingeniería, Medellín, Colombia. E-mail: rdvasquez@elpoli.edu.co

* Autor de correspondencia: jgallardo@ucn.cl
} 


\section{INTRODUCCIÓN}

El proceso de Hidrometalurgia del cobre está compuesto por las etapas de Lixiviación (LIX) del cobre, Extracción por Solvente (SX) y Electro-obtención (EW) y se constituye en uno de los más importantes métodos de producción de cobre desde minerales oxidados de baja ley [9]. La investigación en este proceso ha sido enfocada principalmente en los procesos químicos y equipos asociados. Hasta el presente el control de los procesos de SX-EW ha recaído sobre simples lazos de control y sintonía manual con operadores manipulando activamente los set-point (SP) para controladores de nivel básico o de primer nivel [9, 5]. Un factor que reduce la eficiencia de plantas de SX es la metodología reactiva que los operadores de estas plantas están obligados a realizar, basados en el análisis de los flujos en laboratorio, los cuales ya han sido procesados en la planta [11]. Los ingenieros de proceso utilizan estos análisis after-the-fact para predecir los mejores parámetros de operación para el subsecuente período de operación. Estos parámetros de operación predichos resultan en ajustes manuales para los parámetros del proceso, los cuales en caso de ser correctos, facilitan una mayor extracción de cobre y un rechazo más alto a las impurezas. El nivel de éxito de estas decisiones está sujeto a cómo tan bien el staff operacional, interpreta el estado de la planta en un momento dado (Navarro, Jara y Castillo) [11], han utilizado análisis de imágenes con regresiones lineales y análisis de componentes principales para la estimación de calidad en cobre, y han demostrado resultados exitosos con errores inferiores al 1,5\%.

Uno de los motivos de esta forma de operar plantas de SX, es la falta de medidores en línea de las variables operacionales más relevantes del proceso, como son: la Razón Orgánico-Acuoso (O/A), el Tiempo de Separación de Fases (TSF) y las Concentraciones de Cobre.

De acuerdo a estudios realizados, variables críticas que afectan la calidad del producto y la eficiencia operacional de este proceso son la razón O/A y el tiempo de separación de fases. Un mayor monitoreo y control de estas variables operacionales incide en una mayor recuperación de cobre desde el mineral y un menor consumo de insumos [1].

Es importante resaltar que las razones de fases tienen una incidencia notoria en la extracción, quedando demostrado que cuanto menor sea el flujo de solución orgánica, respecto al flujo de solución acuosa, más baja será la extracción. Además la relación de las fases $\mathrm{O} / \mathrm{A}$ en un mezclador, tiene un efecto significativo sobre el arrastre de orgánico o acuoso. El arrastre de orgánico produce pérdidas importantes de este extractor y contaminación que puede afectar incluso en el proceso de electro-obtención. Adicionalmente, otra razón importante para mantener la relación O/A en su punto de trabajo, es mejorar la velocidad de transferencia de masa y la eficiencia de etapa. Por los motivos antes expuestos es que se debe llevar un control periódico de la razón $\mathrm{O} / \mathrm{A}$, con medidas confiables y precisas $[10,12]$.

El tiempo de separación de fases se refiere al tiempo necesario que se debe dejar en reposo la emulsión para la separación de las fases acuosa y orgánica. Con tiempos de retención adecuados, se logra separar totalmente las fases evitando de esta manera los atrapamientos de orgánico y acuoso. Los controles de tiempo de separación de fases deben registrarse periódicamente porque permiten a partir de estos registros, determinar si el orgánico está sufriendo alguna degradación o algunos contaminantes se han incrementado, producto de arrastres. La calidad de la operación de una planta de SX se basa en minimizar los arrastres que puedan perjudicar operaciones posteriores y que entorpezcan los intercambios de caudales de una etapa a otra [12].

A pesar de la importancia que representa tener medidas precisas y oportunas de estas dos variables operacionales, de acuerdo a la investigación realizada, las plantas de SX en Chile y en el mundo no poseen medidores en línea, de la razón O/A y del tiempo de separación de fases.

En este artículo se presenta el desarrollo de un analizador en línea, que mide la Razón Orgánico Acuoso (O/A) y el Tiempo de Separación de Fases (TSF) utilizando procesamiento de imágenes y un sistema automatizado para la secuencia de la toma de muestras para su medición. Este artículo está estructurado como sigue: en la siguiente sección se describe el proceso metalúrgico, posteriormente se presenta un esquema general del instrumento con una descripción de cada una de sus partes y el principio de medición utilizado. Continuando se muestran los resultados de las pruebas. Finalmente en las últimas secciones se presentan 
respectivamente las conclusiones y un listado de los estudios consultados.

\section{PROCESO METALÚRGICO}

La explotación de minerales constituye una de las principales actividades económicas de Chile. Más concretamente, la producción y exportación de Cobre, representan una importante fuente de ingresos para el país [16].

El Cobre es un mineral que se encuentra en la naturaleza en forma de cobre sulfurado y/o cobre oxidado, y es en función del tipo de cobre que se encuentre en un determinado yacimiento, el tipo de método aplicado para su explotación. Básicamente son dos los métodos utilizados en función de las características del mineral: La pirometalurgia y la hidrometalurgia.

El método convencional para la extracción del cobre, se denomina pirometalurgia o también conocido como fundición y es utilizado para procesar el sulfuro de cobre.

Otro método utilizado en la producción de cobre es el denominado hidrometalurgia. La hidrometalurgia también conocida como lixiviación (LIX), extracción por solvente y electro-obtención (SX/EW), de sus siglas en inglés [4], es un proceso que permite la extracción del cobre a temperatura ambiente, reduciendo drásticamente el consumo de energía. Este método es uno de los más importantes para la producción de cobre desde minerales oxidados de baja ley y no surge como un sustituto para la pirometalurgia, sino más bien como un proceso complementario ya que el cobre se encuentra en la naturaleza en un $80 \%$ en estado sulfurado, el cual solo puede ser extraído a través de su fundición.

\section{LIXIVIACIÓN (LIX)}

Esta etapa es utilizada siempre y cuando el mineral en la naturaleza se encuentre en su estado oxidado. La lixiviación [6], es la etapa en la cual se realiza un proceso hidrometalúrgico que consiste en provocar la disolución de un elemento, en este caso el cobre, desde el mineral que lo contiene, para ser recuperado posteriormente mediante electrólisis.

El material apilado debe ser regado con una solución lixiviante, a través de un sistema de cañerías que pueden estar instaladas bajo la superficie de las pilas. Se irriga el material por goteo, o mediante un sistema de aspersores tipo wobblers o sprinklers. La solución lixiviante y el mineral producen una serie de etapas secuenciales que consisten fundamentalmente de un proceso de difusión y un ataque químico sobre el material ${ }^{8}$ (Figura 1).

Canaletas de recolección transportan las soluciones resultantes del producto de lixiviación. Dos secciones dividen a las canaletas para que sea posible conducir por gravedad y de forma separada e independiente soluciones ricas y pobres en mineral, las que finalmente son clasificadas y depositadas en piscinas que pueden ser:

- Piscinas ricas en solución (PLS).

- Piscinas de solución intermedia (ILS).

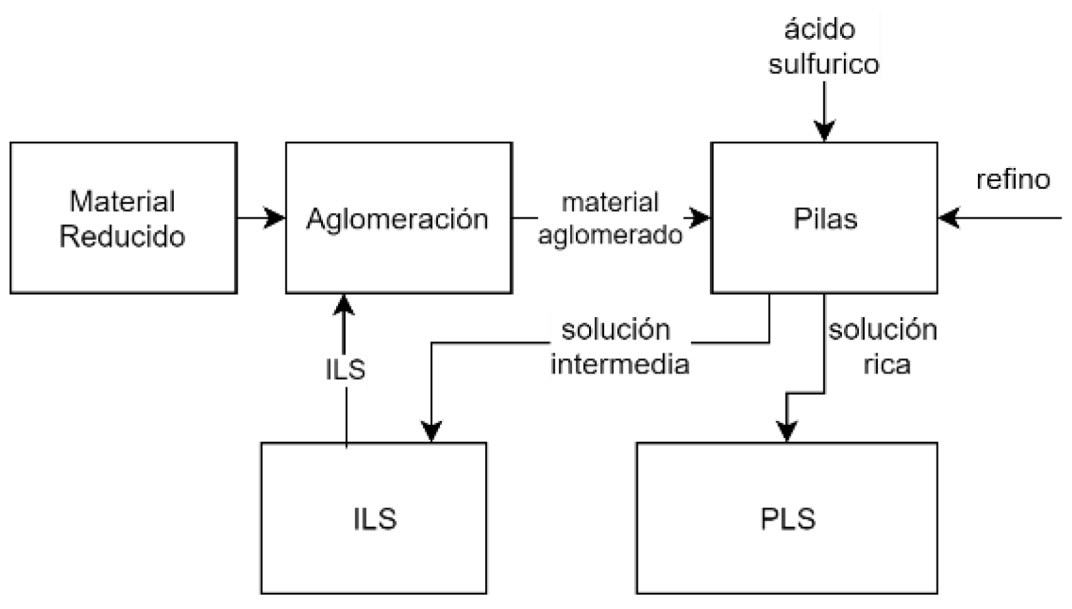

Figura 1. Proceso de lixiviación [8]. 
El ILS es utilizado para regar el aglomerado y generar PLS.

\section{EXTRACCIÓN POR SOLVENTE (SX)}

La extracción por solventes (Figura 2) permite extraer el cobre de la solución PLS utilizando una resina orgánica diluida en un solvente orgánico (parafina) [7]. La resina captura el cobre y lo separa de impurezas (hierro, aluminio, manganeso, entre otros).

\section{ELECTRO-OBTENCIÓN (EW)}

La electro-obtención es una de las últimas etapas en el procesamiento [8] y producción del cobre a partir de un mineral oxidado y es un proceso electrometalúrgico, el cual consiste en hacer circular una corriente de muy alta intensidad entre dos terminales, Ánodo y cátodo, sumergidos en una solución electrolítica concentrada (rica en partículas de cobre) [7].

\section{DISEÑO Y DESARROLLO DEL ANALIZADOR}

La Figura 3, representa un estanque mezcladordecantador típico de los procesos de extracción y reextracción utilizados en plantas hidrometalúrgicas, para la obtención de cátodos de cobre. Se observa en esta figura, la probeta con la cual se mide actualmente ambas variables operacionales y el lugar donde se toma la muestra.

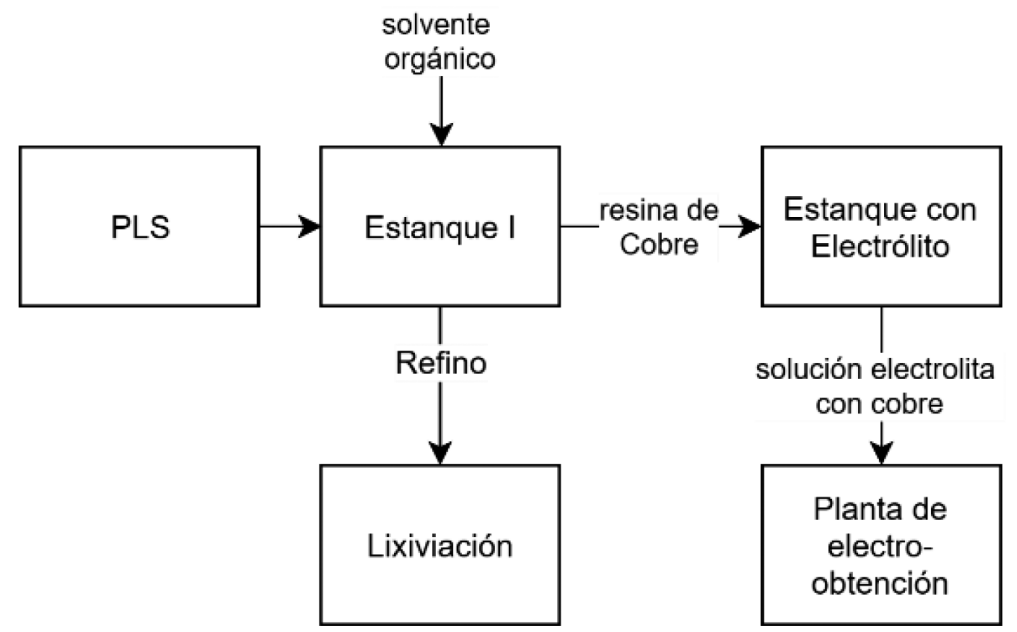

Figura 2. Proceso de extracción por solvente [8].

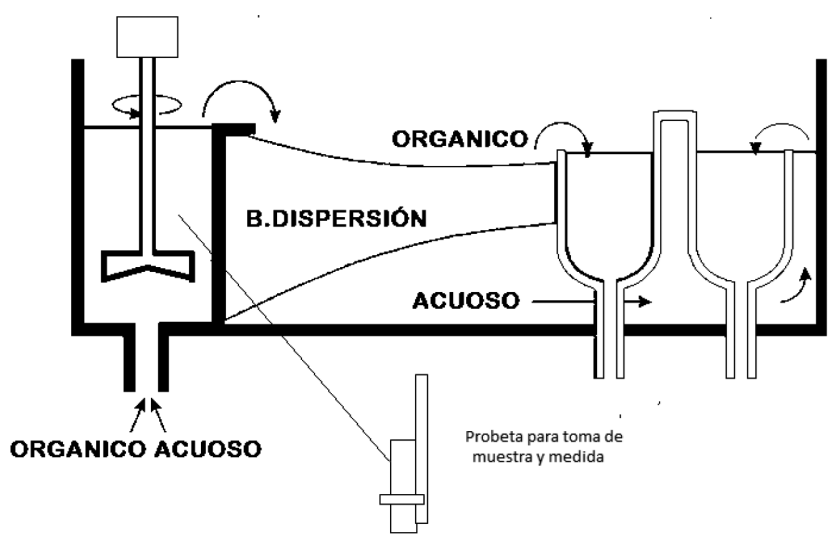

Figura 3. Estanque mezclador-decantador, probeta y lugar de medición de las variables. 
La técnica actual para medir estas variables se basa en una interpretación visual de la altura de cada fase (acuosa y orgánica) y el tiempo que tardan en separarse, lo cual ya ha sido realizado por otros autores como Vargas M. [14] para el análisis de partículas en la fase orgánica. Para tomar la muestra, se utiliza una probeta de vidrio graduado de $1000 \mathrm{cc}$, que es sumergida y manipulada por el operador dentro del estanque mezclador primario (Figura 4). Esta acción en sí es una acción riesgosa para los operadores encargados de realizar las medidas en un ambiente contaminado, luego para medir el tiempo de separación de fases se emplea un cronómetro y el corte de la medida es determinado por el operador. El resultado o calidad de la medida dependerá principalmente de la pericia del operador, la cual puede ser una fuente de error. Las mediciones se realizan, aproximadamente con una frecuencia de cada dos horas. No existen otras formas de medición de estas variables en ningún proceso similar a nivel mundial. Existe una técnica similar, utilizando procesamiento de imágenes, para medir concentraciones de cobre desarrollada por los mismos autores de este artículo [2].

\section{PRINCIPIO DE MEDICIÓN Y TECNOLOGÍA IMPLEMENTADA}

La tecnología propuesta se basa en la técnica de tratamiento de imágenes, aplicada a cada muestra

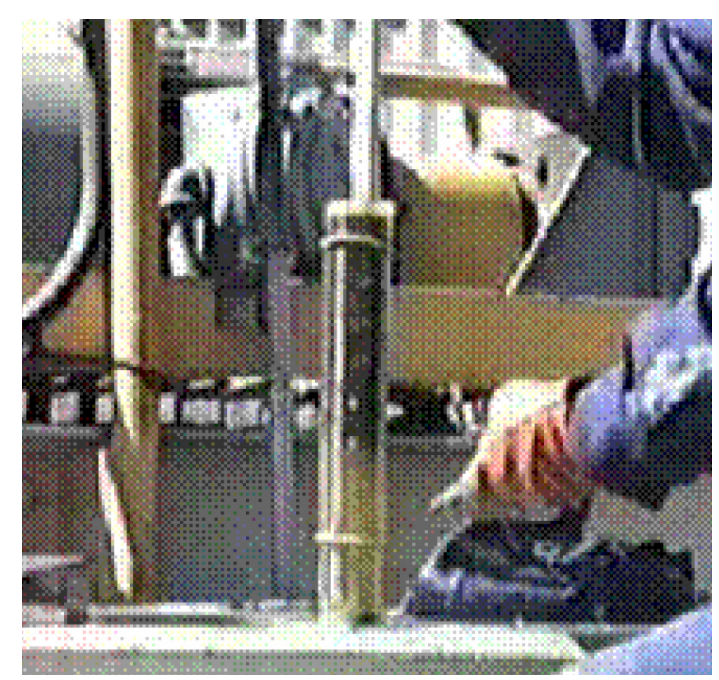

Figura 4. Foto real de la técnica de toma de muestra para la Medición de la razón O/A y del TSF (Tiempo de separación de fase). tomada desde el proceso. Este proceso se realiza mediante un programa de reconocimiento de imágenes desarrollado especialmente para poder determinar las variables en estudio. La toma de la muestra y su procesamiento es automatizado para lograr la medición en línea, utilizando un controlador lógico programable, diversos circuitos hidráulicos, una serie de válvulas y una bomba de succión.

\section{ESQUEMA DE MEDICIÓN}

La Figura 5 representa el esquema del sistema para la medición en línea de la concentración de cobre. Mediante una bomba de succión se extrae la muestra de acuoso en la salida de cada decantador donde se desea obtener una medida de la razón O/A y el tiempo de separación de fases. Esta muestra se deposita en una probeta de vidrio, previamente sometida a un lavado con agua controlada por una válvula solenoide para cada muestra. Luego, en forma sincronizada, se toman imágenes de la muestra mediante una cámara y se procesa la información en un computador dedicado. Esta secuencia se vuelve a repetir periódicamente en un tiempo que debe ser fijado por el usuario.

En general, se utilizan válvulas solenoides para la operación del equipo, además de un sistema de control basado en un PLC para comandar la secuencia de operaciones en el proceso de medición.

La Tabla 1 muestra direcciones, tipo y descripción de las variables utilizadas en la construcción del diagrama de estados (Figura 6) a partir del cual se construye el algoritmo de control en el PLC.

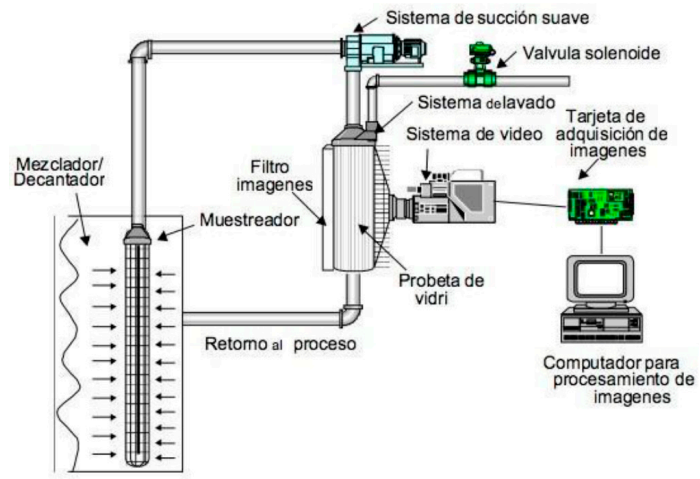

Figura 5. Diagrama esquemático del instrumento de medición. 
Tabla 1. Dirección, tipo y descripción de variables.

\begin{tabular}{|c|l|l|}
\hline Dirección & \multicolumn{1}{|c|}{ Tipo } & \multicolumn{1}{c|}{ Descripción } \\
\hline M0.1 & Estado & Reposo \\
\hline M0.2 & Estado & Vaciado \\
\hline M0.3 & Estado & Lavado \\
\hline M0.4 & Estado & Recirculando \\
\hline M0.5 & Estado & Bombeo muestra \\
\hline M0.6 & Estado & Lavado finalizado \\
\hline M0.7 & Estado & Recirculación finalizada \\
\hline M1.0 & Estado & Fin recirculación y procesamiento de imagen. \\
\hline I0.1 & Entrada & Pulsador de inicio y término (NA) \\
\hline I0.2 & Entrada & Sensor de Nivel (NA) \\
\hline B3.0 & Entrada & Bit início de Proc. de Imagen \\
\hline t1 & Temporizador & Vaciado \\
\hline t2 & Temporizador & Lavado \\
\hline t3 & Temporizador & Recirculación \\
\hline Q0.1 & Salida & Válvula de llenado \\
\hline Q0.2 & Salida & Válvula de lavado \\
\hline Q0.3 & Salida & Válvula de recirculación \\
\hline Q0.4 & Salida & Válvula de retorno \\
\hline Q0.5 & Salida & Bomba succión de muestra \\
\hline Q0.6 & Salida & Inicio de procesamiento de imagen \\
\hline
\end{tabular}

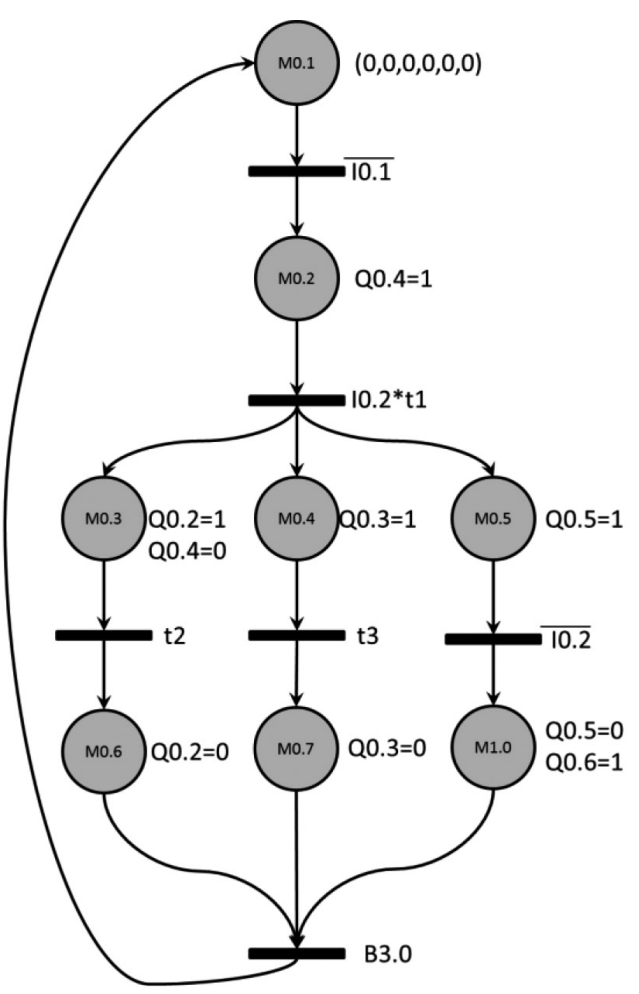

Figura 6. Diagrama de estado del proceso de toma de muestras.

\section{PROCESAMIENTO DE LAS IMÁGENES}

Inicialmente. para el proceso de tratamiento de imágenes, fue necesario considerar el modo "color", procedimiento mediante el cual se almacenaron temporalmente las imágenes muestreadas en formato BMP, utilizando el modo RGB de 24 bits [3]. Las imágenes, en formato BMP, permiten una recuperación más sencilla que formatos tales como el JPG que es un formato comprimido y, por tanto, se requeriría conocer el algoritmo de compresión para poder trabajar la imagen.

Posteriormente a la realización de múltiples mediciones y pruebas de algoritmos, se optó por convertir las imágenes capturadas a su escala de tonos grises, que es una escala empleada en la imagen digital en la que el valor de cada píxel posee un valor equivalente a una graduación de gris. Las imágenes, representadas de este tipo, están compuestas de diferentes niveles de grises, las cuales, en relación al contraste que presentan, definen claramente el orgánico y el acuoso.

El proceso se inicia con todos los actuadores (salidas) apagados. Una vez que se presiona el pulsador de inicio, comienzan simultáneamente las acciones de 
lavado, recirculación y bombeo de la muestra. El lavado y recirculación son estados temporizados, es decir, finalizan cuando un tiempo predeterminado se ha cumplido, mientras que el bombeo de muestra finaliza cuando se detecta nivel alto. En este momento se inicia todo el proceso de visión artificial para la medición de la razón O/Ay el TSF. Una vez que el proceso se estabilice, el proceso recibirá la confirmación en B3.0 y podrá iniciar nuevamente.

En la Figura 7 se presenta el diagrama de flujo del algoritmo implementado. Este algoritmo empieza con el preprocesamiento de la imagen que incluye enmascaramiento, luminancia, umbralización, cierre, filtrado y conversión a convexa, de modo que se pueda obtener una imagen, donde la parte orgánica en la parte superior y acuosa en la parte inferior, se puedan diferenciar como ceros y unos respectivamente. Luego se convierte a escala de grises con una ecualización, para convertir los unos a valores de 255, lo cual permite implementar algoritmos de detección de bordes para poder obtener la razón O/A y el TSF.

Se agrega una opción para ajustar la luminancia, valor que es utilizado en el algoritmo de conversión a escala de grises de la imagen que se está adquiriendo. En este menú, el usuario puede elegir un valor umbral para el cual los valores de las luminancias inferiores a éste serán considerados negros y los superiores serán considerados blancos.

Al cargar el programa se tiene por defecto un umbral de 128 , seleccionado para convertir la imagen a blanco y negro. Para efectos de calibración de este analizador,

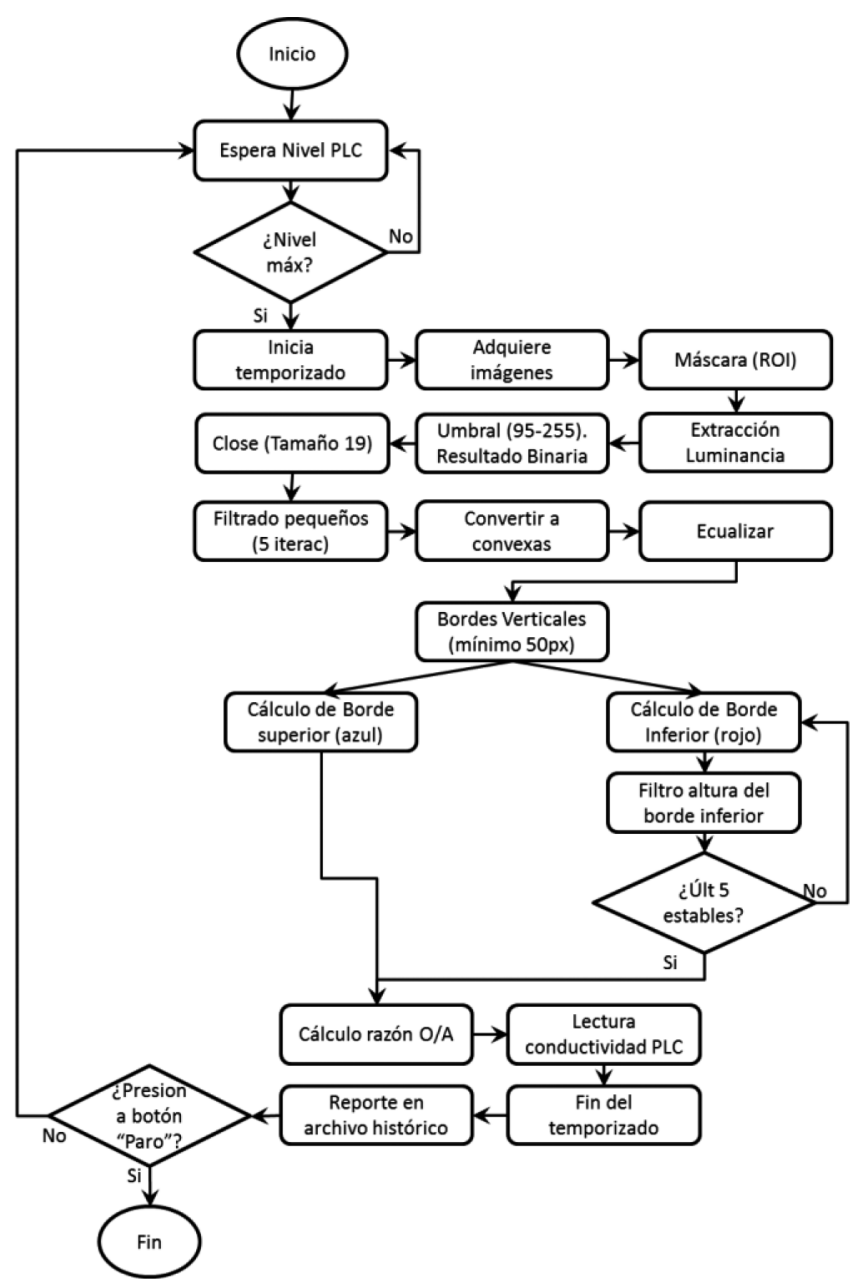

Figura 7. Diagrama de flujo del algoritmo de visión artificial. 
se deja variable esta opción, debido que muchas veces el material (orgánico-acuoso) no presenta las mismas tonalidades de colores, dependiendo éstas de factores como: el tipo de material utilizado, las proporciones de cada uno y la velocidad de agitación. Por esto, el procesamiento de imagen no sería el mismo y no se podría llevar a cabo.

Una vez ajustada la Luminancia de la imagen, ya se puede comenzar a tomar pruebas del tiempo de separación de fases y la razón orgánico-acuoso, lo cual se realiza mediante el cálculo constante de los límites entre ambas sustancias y, una vez se detecte su estabilidad en cinco mediciones sucesivas, se toman los datos para calcular la razón O/A y TSF.

Finalmente el la Figura 8 se presenta una vista interior del instrumento desarrollado y la Figura 9 presenta una captura de pantalla del proceso de medición que realiza el analizador.

Los componentes utilizados en el analizador son los siguientes:

- PLC Micrologix 1100, Allen Bradley.

- PC: Lenovo, Core i3.

- Software Labview para el procesamiento de imagen.

- Cámara.

- Iluminación: lampara Led, 12 watts.

\section{ANÁLISIS DE RESULTADOS}

Las mediciones se efectuaron en una probeta de vidrio, graduada de 1 litro de capacidad y a una

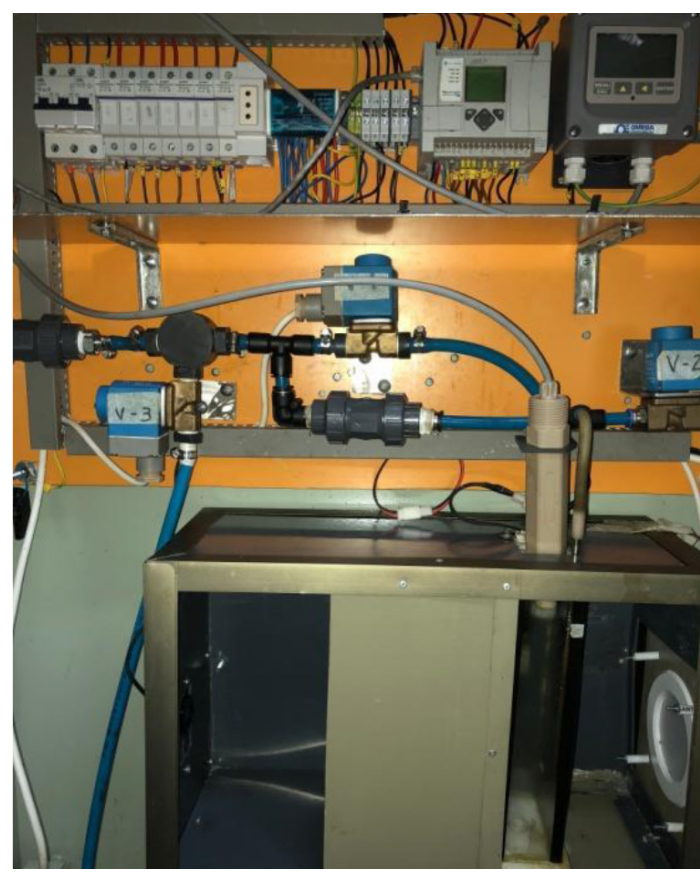

Figura 8. Vista interior del analizador.

velocidad de agitación de mezcla de 468 RPM. El procedimiento consistió en tomar muestras del estanque mezclador y medir la razón O/A y el tiempo de separación de fases con el analizador en distintas situaciones de tiempo de agitación y razón O/A. Para efectos de comparación, se utilizó un cronómetro digital y una regla graduada en milímetros para medir el tiempo de separación de fases y la razón O/A en cada medición, utilizando el procedimiento manual aplicado en las plantas de SX.

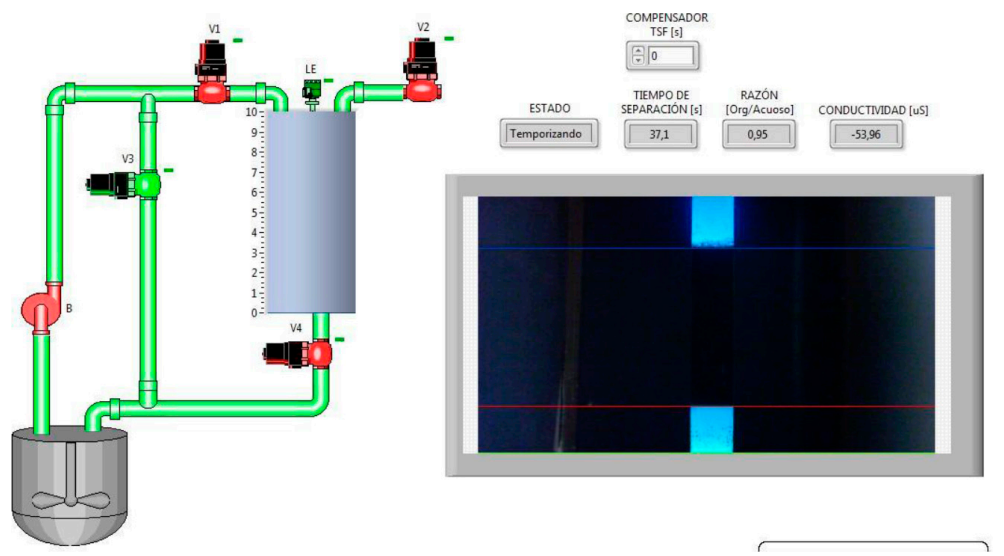

Figura 9. Proceso de medición. 
Los resultados obtenidos de las distintas mediciones de la razón O/A se muestran en la Tabla 2, para distintas razones $\mathrm{O} / \mathrm{A}$, cercanas a 1:1.

Los resultados obtenidos en la medición del tiempo de separación de fases se muestran en la Tabla 3, para las distintas razones $\mathrm{O} / \mathrm{A}$, registradas en la Tabla 2.

De acuerdo con los resultados experimentales obtenidos, se observa que el analizador presenta un error relativo promedio menor a un $2 \%$ para la medición de la razón O/A y un error relativo promedio menor a un $1 \%$ para la medición del TSF.

Es importante señalar, para efectos de control, que el tiempo que demora el analizador en entregar cada medición, debe ser bastante menor que la constante de tiempo de la planta a controlar, típicamente 10 veces menor. En este caso, el tiempo que demora el analizador en medir tiene que ver con el tiempo de separación de fases de la mezcla en el estanque mezclador. Los valores típicos de los tiempos de separación de fases son menores a 3 minutos. Si a este tiempo se suma el tiempo de retorno de la muestra al proceso y el tiempo de lavado del recipiente de vidrio, se puede considerar que la demora de este analizador en entregar las mediciones es de aproximadamente 4 minutos. Para plantas de SX, este es un tiempo adecuado para que el analizador en desarrollo no afecte el desempeño del lazo de control.

\section{CONCLUSIONES}

Los resultados que se obtuvieron en las pruebas experimentales muestran que el analizador presenta un error relativo promedio menor a un $2 \%$. Con el prototipo industrial se espera poder realizar una mayor cantidad de pruebas y mediciones para determinar los diferentes parámetros estáticos y dinámicos propios de un instrumento de medición,

Tabla 2. Medidas de la Razón O/A con relación Orgánico-Acuoso en torno a 1:1.

\begin{tabular}{|c|c|c|c|c|}
\hline Muestra & Razón O/A Manual & Razón O/A Analizador & Error Abs & Error Relat \% \\
\hline 1 & 1,059 & 1,078 & 0,019 & 1,794 \\
\hline 2 & 1,120 & 1,141 & 0,021 & 1,875 \\
\hline 3 & 1,268 & 1,287 & 0,019 & 1,498 \\
\hline 4 & 1,166 & 1,187 & 0,021 & 1,801 \\
\hline 5 & 1,102 & 1,121 & 0,019 & 1,724 \\
\hline 6 & 1,095 & 1,115 & 0,020 & 1,826 \\
\hline 7 & 1,270 & 1,293 & 0,023 & 1,811 \\
\hline 8 & 1,068 & 1,087 & 0,019 & 1,779 \\
\hline 9 & 1,274 & 1,293 & 0,019 & 1,491 \\
\hline 10 & 1,073 & 1,094 & 0,021 & 1,957 \\
\hline Promedio & 1,149 & 1,169 & 0,02 & 1,741 \\
\hline
\end{tabular}

Tabla 3. Medidas de tiempo de separación de fases.

\begin{tabular}{|c|c|c|c|c|}
\hline Muestra & TSF Manual & TSF Analizador & Error Abs. Seg. & Error Relat. \% \\
\hline 1 & 87 & 87,31 & $-0,31$ & $-0,35$ \\
\hline 2 & 88 & 89,58 & $-1,58$ & $-1,79$ \\
\hline 3 & 88 & 89,65 & $-1,65$ & $-1,87$ \\
\hline 4 & 87 & 86,62 & 0,38 & 0,43 \\
\hline 5 & 90 & 88,92 & 1,08 & 1,20 \\
\hline 6 & 91 & 87,91 & 3,09 & 3,39 \\
\hline 7 & 91 & 87,83 & 3,17 & 3,48 \\
\hline 8 & 90 & 89,86 & 0,14 & 0,15 \\
\hline 9 & 89 & 88,18 & 0,82 & 0,92 \\
\hline 10 & 90 & 89,50 & 0,50 & 0,55 \\
\hline Promedio & 89 & 88,54 & 0,56 & 0,61 \\
\hline
\end{tabular}


pruebas que se espera concretar en una faena real o en un laboratorio piloto de certificación de calidad.

Indudablemente que el uso de imágenes en conjunto con un procesamiento computacional adecuado, asegura un comportamiento estable y una buena precisión en las mediciones.

Al automatizar la medición se logra mejorar la repetibilidad de las mediciones debido a la sistematicidad en la forma en que se toma la muestra y se realiza su análisis, en contraste a la forma en que se mide en la actualidad. Además se elimina el peligro de accidentes y exposición a un ambiente tóxico para el personal encargado de realizar las mediciones en terreno.

Finalmente se debe destacar que esta innovación, se encuentra protegida con una patente industrial otorgada por INAPI (Chile), con número de registro 2011-003130 y con fecha 09/06/2016.

\section{AGRADECIMIENTOS}

Se agradece al Centro Empresarial para la Elaboración de Tecnologías Avanzadas (Brasil), a 3M Ltda (Chile), a la Universidad Católica del Norte (Chile) por el aporte de componentes y laboratorios para la realización de pruebas a nivel industrial y al Grupo ICARO del Politécnico Colombiano JIC, por su participación en el mejoramiento del algoritmo para el procesamiento de las imágenes.

\section{REFERENCIAS}

[1] Addere Ltda. "Estudio de identificación de oportunidades para la industria de tecnologías de información y comunicaciones en el cluster minero". InnovaChile CORFO, p. 235. 2009.

[2] C. Ayala, J. Gallardo y M. Olivares. "Desarrollo de un Analizador en línea, de las concentraciones de Cobre en soluciones acuosas del proceso de Extracción por Solvente, mediante procesamiento de imágenes". RISTI No 24, pp. 1-12. 2017.

[3] A. Sivanantha Raja and K. Sankaranarayanan. "Use of RGB Color Sensor in Colorimeter for better Clinical measurement of Blood". Glucose BIME Journal. Vol. 06, Issue 1. 2006.

[4] J. Beckel. "El proceso hidrometalúrgico de lixiviación en pilas y el desarrollo de la minería cuprífera en Chile. Red de Reestructuración y competitividad División de Desarrollo Productivo y Empresarial". CEPAL, Naciones Unidas. 2000.

[5] J.G. Bergh, S.L. Jämsä-Jounela and D. Hodouin. "State of the art in copper hydrometallurgical processes control". Control Engineering Practice. Vol. 9, pp. 1007-1012. 2001.

[6] J. Fernandez. "Lixiviación de sulfuros de baja ley, planta de óxidos división el soldado". Tesis para optar al grado de Ingeniero Civil Químico. Escuela de Ingeniería Química, Pontificia Universidad Católica de Valparaíso, p. 3. 2013.

[7] DIM_USACH. "Introducción a la Metalurgia". 2018.

[8] I. Donoso y L. San Martín. "Procesos productivos del cobre". (No publicado) 2018.

[9] T. Komulainen, F. Doyle III, A. Rantala and S.L. Jämsä-Jounela. "Control of an industrial copper solvent extraction process". Journal of Process Control. Vol. 19, pp. 2-15. 2009.

[10] SX. Kinetics, Inc. "Efectos de la relaciones de faces Organica y Acuosa (O/A) y la fase de continuidad". 2018. URL: http://www. sxkinetics.com/spanish/entrainment.sp.htm

[11] M. Mwale and D. Megaw. "Development of effective solvent-extraction process control low cost implementation value-addition to hydrometallurgical copper operations". Southern African Institute of Mining \& Metallurgy, Johannesburg, pp. 353-365. 2011.

[12] D. Navarro, S. Jara M. and J. Castillo S. "Problemas en la separación de fases en extracción por solvente de cobre". Remetallica, Año 31 № 15. 2013.

[13] A. Newman. "A Review of Operations Research in Mine Planning". Interfaces. Vol. 40, Issue 3, pp. 222-245. 2010. DOI: 10.1287.

[14] J. Tamminen, E. Lahdenperä, T. Koiranen, T. Kuronen, T. Eerola, L. Lensu and H. Kälviäinen. "Determination of single droplet sizes, velocities and concentrations with image analysis for reactive extraction of copper". Chemical Engineering Science. Vol. 167, pp. 5465. 2017.

[15] M. Vargas. "Modelo de planificación minera de corto y mediano plazo incorporando 
restricciones operacionales y de mezcla". Tesis para optar al grado de Magíster en Minería, Departamento de Ingeniería de Minas, Universidad de Chile, pp. 2, 26, 30, 57, 59. 2011.

[16] X. Yuan, H. Zhang and Z. Song. "A softsensor for estimating copper quality by image analysis technology". 10th IEEE International Conference on Control and Automation (ICCA), pp. 991-996. 2013.

[17] M. Donoso. "El mercado del cobre chileno frente a la problemática financiera internacional". Ingeniare. Revista chilena de ingeniería. Vol. $22 \mathrm{~N}^{\circ}$ 1, pp. 99-115. 2014. 